\title{
O Dilema do Prisioneiro e a Ineficiência do Método das Opções Reais
}

\section{The Prisoner's Dilemma and the Inefficiency of the Real Options Method}

André Barreira da Silva Rocha*

Doutorando em Economia na Universidade de Essex, Reino Unido.

*Endereço: Av. Epitácio Pessoa, 2800, apto. 302, Lagoa, Rio de Janeiro/RJ, 22471-003.

E-mail: abarre@essex.ac.uk 


\title{
ResUMo
}

No campo financeiro, existe uma idéia amplamente difundida de que o emprego do método das opções reais na avaliação de um projeto ou gestão de um negócio resulta em valores superiores àqueles obtidos por técnicas ortodoxas (Valor Presente Líquido). O objetivo deste artigo é desmistificar tal conceito, demonstrando que quando se leva em conta corretamente o efeito da concorrência, o emprego de técnicas ortodoxas de avaliação ou de gestão pode conduzir os gerentes das empresas a tomarem decisões estratégicas capazes de gerar lucros superiores àqueles que seriam obtidos ao empregar opções reais. Isso é demonstrado através da modelagem de um mercado duopolista, sujeito a incertezas, sendo calculado e comparado o lucro esperado para uma das empresas segundo três conceitos de gestão: método ortodoxo; opções reais exclusivas e opções reais comuns. Os resultados do modelo mostram que, dependendo do tipo de opção real disponível, uma situação de dilema do prisioneiro pode ocorrer, sendo neste caso a gestão por opções reais ineficiente, quando comparada ao método ortodoxo.

Palavras-chave: opções reais; jogos; avaliação; estratégia; duopólio.

\begin{abstract}
In the financial field, there is a widely spread out idea that the use of the real options method in the valuation of a project or management of a business results in larger values than those obtained by orthodox techniques (Net Present Value). The purpose of this paper is to demystify such concept, demonstrating that when the effect of competition is correctly taken into account, the use of orthodox techniques of valuation or management can lead the companies' managers to take strategic decisions capable to generate larger profits than those that would be generated through the use of real options. This is demonstrated through the modeling of a duopolistic market subjected to uncertainties, being calculated and compared the expected profit for one of the companies according to three concepts of management: orthodox method; exclusive real options and common real options. The results of the model show that depending on the type of available real option, a situation of prisoner's dilemma can occur, in this case the management through real options being inefficient when compared with the orthodox method.
\end{abstract}

Key words: real options; games; valuation; strategy; duopoly. 


\section{INTRODUÇÃO}

$\mathrm{Na}$ literatura das finanças corporativas, o método das opções reais constitui uma ferramenta atual e moderna de avaliação de projetos e também de gestão de negócios. Também é um método para o qual existe uma idéia, amplamente difundida no campo das finanças, de que o seu emprego na avaliação de um projeto conduz a valores superiores àqueles obtidos por técnicas ortodoxas de avaliação. Porém, dentro do mundo empresarial, ainda hoje muitas atividades operacionais e muitos projetos de investimento são avaliados e geridos segundo técnicas ortodoxas onde, basicamente, se estimam receitas e despesas futuras de modo a projetar os fluxos de caixa das empresas, sem levar em conta fatores fundamentais como risco e concorrência. Um exemplo clássico de metodologia de avaliação ortodoxa deste gênero é o conhecido método do Valor Presente Líquido [VPL]. É possível gerir uma empresa ou avaliar um projeto desta forma, mas há sérias limitações, especialmente quando se está lidando com projeções de resultados de longo prazo em setores sujeitos a fortes incertezas. Daí a importância da evolução que ocorreu na área financeira, com o surgimento da abordagem gerencial por meio das opções reais na década de 1970, a qual é bastante superior, em termos de modelagem, quando comparada aos métodos ortodoxos, uma vez que permite levar em consideração na análise futura de um negócio as suas flexibilidades, devido às diferentes decisões gerenciais que podem vir a ser tomadas de acordo com os cenários futuros passíveis de ocorrer em contextos de incertezas significativas. Tais flexibilidades são modeladas de forma semelhante a uma opção negociada no mercado de capitais, cujo detentor tem o direito, mas nunca a obrigação de exercê-las. Conforme Lopes (2004), se o custo da mudança de estratégia pela empresa for baixo e as incertezas do setor elevadas, a gestão por meio das opções reais, que envolve um conjunto de alternativas estratégicas flexíveis, mostra-se mais adequada que métodos tradicionais, que selecionam uma única estratégia dentre um conjunto mutuamente excludente e tomam o cenário que lhe deu origem como sendo o retrato fiel do que ocorrerá no futuro para o setor e para a empresa.

Apesar da superioridade das opções reais, seu uso na indústria ainda é muito limitado, devido, dentre outros aspectos, ao fato de as qualificações de muitos gerentes empresariais estarem aquém da complexidade que os modelos envolvem. Além da ainda baixa difusão da gestão de negócios e avaliação de projetos através das opções reais, outra limitação no mundo empresarial diz respeito às empresas que já empregam o método, porém o fazem de maneira inadequada. Um problema comum é a consideração da exclusividade das opções reais, avaliadas unicamente para a empresa em análise, deixando-se de considerar o fato de que, se o cenário 
for favorável para a empresa, este provavelmente também será para as suas concorrentes, podendo levar a que todas ou algumas empresas daquele mercado também possam exercer suas opções reais simultaneamente, conduzindo isso a um resultado final pior do que se a opção real fosse realmente exclusiva da empresa em análise. Há casos, como mercados monopolistas, em que de fato uma empresa goza de exclusividade sobre o direito de exercer uma opção real que ela detenha. Porém há muitas indústrias em que não existe exclusividade; este é um detalhe importante, por vezes não tratado, quando se emprega o método das opções reais. Tal problema é relevante, uma vez que não está restrito à prática do mundo empresarial, podendo ser observado também nos trabalhos teóricos. Pereira e Armada (2003) alertam para a questão de que a competição é ignorada freqüentemente na literatura, com muitos modelos de opções reais admitindo que a opção é exclusiva de uma única empresa. Perlitz, Peske e Schrank (1999) também enfatizam como diferença fundamental entre as opções reais e financeiras o aspecto de as primeiras serem influenciadas pelo ambiente competitivo que transforma opções reais exclusivas em opções reais comuns a todas as empresas. Segundo Copeland e Antikarov (2002), um dos problemas, ao se analisarem modelos pela teoria das opções reais, está em ignorar os efeitos sobre ele das decisões do corpo gerencial da empresa e também da reação de seus concorrentes a cada decisão tomada. Uma evolução na literatura das opções reais, para dar melhor tratamento a este problema, deu-se pela combinação da mesma com a teoria dos jogos, em que se avalia o exercício das opções disponíveis, levando em conta também as ações de todas as empresas presentes naquele mesmo mercado.

O objetivo deste trabalho é comparar o lucro esperado de uma empresa segundo três situações, que representam os três padrões descritos acerca da maneira de se avaliar um projeto ou gerir uma empresa, e demonstrar que o emprego da avaliação ou gestão por opções reais, considerando o efeito da concorrência, nem sempre aumenta o lucro esperado e o valor da empresa, quando comparado à utilização de métodos ortodoxos, apesar de ser o método que descreve a realidade de maneira mais fiel. A primeira das situações analisadas é quando se ignora a existência das flexibilidades gerenciais; a segunda quando se leva em consideração a existência das opções reais, porém se admite que elas são exclusivas de uma única empresa; a terceira quando se admite que as opções reais existem e são comuns a todas as empresas do mercado. Neste terceiro caso, é considerada ainda uma hipótese adicional: a empresa para a qual se calcula o lucro esperado tem maior poder no mercado, em face de outra, sendo, portanto, uma empresa dominante ou líder na escolha da estratégia a adotar. A última das três análises é a que modela mais corretamente o mundo real, admitindo que não se está analisando um setor que funciona segundo um monopólio. Para atingir o objetivo do trabalho, admite-se um modelo simples de um único período de tempo, quando 
duas empresas competem num mercado regulamentado. Os lucros esperados dependem das estratégias gerenciais adotadas por cada empresa, as quais dependem dos cenários futuros. Uma abordagem inicial e menos abrangente deste problema pode ser vista em Rocha (2005). Os resultados do modelo aqui desenvolvido mostram que, no caso da detenção do direito sobre as mesmas opções reais por parte da concorrência não é considerada, conforme diversos trabalhos da literatura, de fato o método das opções reais sempre conduz a resultados superiores, se comparado à metodologia ortodoxa de gestão. Entretanto, quando se leva em consideração que as opções reais são comuns, mesmo sendo a empresa líder na escolha da estratégia a adotar, se pode verificar que diante de alguns contextos ocorre uma situação similar ao jogo conhecido como Dilema do Prisioneiro, sendo que neste caso a ignorância gerencial acerca da consideração das opções reais, como no caso da metodologia ortodoxa, pode levar a utilização de estratégias que conduzem a lucros superiores do que quando se leva em conta a existência da flexibilidade gerencial, portanto, havendo uma ineficiência do método das opções reais.

\section{Conceito e Tipos de Opções Reais}

O método das opções reais constitui amplo avanço para avaliar investimentos, quando comparado ao método do VPL. Este foi idealizado no início do século XX e, apesar de ainda ser amplamente usado, trata-se de um método de avaliação ideal para ser empregado apenas em decisões que não envolvam incertezas futuras ou em que os gestores não tenham flexibilidade de decisão para reagir ao cenário futuro que venha a ocorrer. Um exemplo cotidiano em que o VPL pode ser empregado de modo adequado é quando se decide entre comprar determinado equipamento ou mercadoria a prazo ou a vista, uma vez que neste caso a taxa de juros, o número e valor das parcelas a prazo e o preço a vista estão perfeitamente definidos, não havendo também a possibilidade de se tomar medidas que possam influenciar os mesmos ao longo do tempo. Entretanto, quando existem incertezas futuras sobre os valores dos fluxos de caixa de um projeto e, além disso, os gestores podem tomar decisões de acordo com o cenário (valor) real que venha a ocorrer para eles, o melhor é utilizar o método de avaliação de projetos por opções reais. Neste método, diz-se que o corpo gerencial da empresa que avalia o projeto dispõe de opções sobre seus ativos reais em que, de forma similar as opções financeiras, seus detentores possuem o direito, mas nunca a obrigação de exercer tais opções. O exercício somente ocorre, se o cenário futuro for favorável à empresa.

Para se fazer a avaliação por opções reais, pode ser usado um modelo discreto de árvore binomial, onde inicialmente, no passo 1, os possíveis valores dos fluxos 
de caixa do empreendimento, considerando a volatilidade mas ainda sem levar em conta a existência da flexibilidade das decisões gerenciais, são calculados em cada nó da árvore. A partir daí, no passo 2, são incorporadas todas as opções reais disponíveis no empreendimento e são calculados os novos fluxos de caixa que seriam obtidos em cada nó da árvore, caso cada opção real seja exercida. $\mathrm{O}$ valor final do fluxo de caixa em cada nó passa então a ser o valor máximo entre cada fluxo de caixa obtido para cada opção real em caso de exercício e o fluxo de caixa inicialmente calculado no passo $1 \mathrm{sem}$ levar em conta a existência das opções. Uma vez definido cada fluxo de caixa final em cada nó da árvore binomial, no passo 3, obtêm-se os valores esperados dos fluxos de caixa em cada período que se descontam com valor presente. É importante ressaltar que se na avaliação, apenas fossem feitos os passos de número um e três descritos acima, se estaria diante de uma avaliação puramente por VPL, apenas levando em conta a possibilidade de existir mais de um cenário futuro. Somente quando se emprega o passo dois, identificando e incorporando as diferentes medidas gerenciais que podem ser tomadas e, além disso, verificando qual a melhor decisão em cada cenário incerto, é que se avalia efetivamente por opções reais. O fato de o método do VPL ser mais antigo e apresentar maior rigidez, não incorporando as flexibilidades gerenciais, faz com que seja algumas vezes chamado de método ortodoxo.

Um exemplo simples que demonstra a superioridade difundida na literatura do método de avaliação por opções reais sobre o VPL seria o caso de um projeto de exploração de gás, onde está disponível uma opção real de abandono. Neste exemplo, uma empresa estrangeira de gás natural recebe proposta de projeto que lhe permite explorar o mercado de uma região durante um ano. Em troca, ela tem de construir e entregar, no final deste ano, um ramal de gás que irá abastecer tal região. O investimento hoje necessário para a construção é de \$37 milhões. O preço do metro cúbico do gás daqui a um ano é de $\$ 4,13$, com probabilidade de ocorrer (neutra ao risco) de 51,6\%, ou $\$ 2,18$ (probabilidade de ocorrer de 48,4\%), sendo que o ramal irá atender uma demanda de 12 milhões de metros cúbicos ao ano. O contrato prevê ainda a opção de, após a construção do ramal, a empresa poder vendê-lo para o Estado por $\$ 30$ milhões no ato da entrega da obra. A taxa de desconto do projeto (livre de risco) é de $6 \%$ ao ano. Se fosse utilizado o método do VPL para analisar este projeto, ele não seria empreendido, visto que, no passo um da avaliação, os fluxos de caixa no final do ano seriam $\$ 49,56$ milhões e \$26,16 milhões, respectivamente para o cenário bom e ruim. Portanto, no passo três, o fluxo de caixa esperado no final do ano um seria de $\$ 38,23$ milhões, o qual descontado com o valor presente pela taxa continuamente composta de $6 \%$ ao ano e computado ao investimento inicial resultaria num VPL de -\$0,992 milhões. Já empregando o método das opções reais que leva em conta a flexibilidade de decisões gerenciais, no passo dois, para o cenário desfavorável, 
seria melhor exercer a opção real de abandono e tomar a decisão de abandonar o projeto, vendendo-o ao Estado por $\$ 30$ milhões. Refazendo os cálculos, o novo VPL seria de $+\$ 0,758$ milhões. Pela nova avaliação, valeria a pena empreender o projeto. É importante ressalvar que o método do VPL acaba por estar implícito na avaliação por opções reais. A diferença fundamental é que, durante o passo dois, são incorporadas as diferentes alternativas (opções reais) na projeção dos fluxos de caixa futuros, sendo o VPL utilizado no passo três para valorar o projeto com tais opções já incorporadas, ou seja, o VPL é o instrumento de valoração das diferentes alternativas no método das opções reais.

Além da opção de abandono, exemplificada acima, existem diversos tipos de opções reais que podem estar disponíveis num projeto ou na gestão de uma empresa, como as opções reais de expansão ou contração (Brennan \& Schwartz, 1985; Pindyck, 1988; Trigeorgis \& Mason, 1987); opções reais de trocar um input ou output (Kensinger, 1987; Kulatilaka, 1993; Margrabe, 1978), sendo um exemplo brasileiro de investimento com opção real de troca de input a decisão de aquisição ou não de um automóvel com motor tipo flex; opções reais de diferimento (Titman, 1985; Tourinho, 1979), onde os gestores podem, por exemplo, aguardar o melhor momento para iniciar a extração de determinado mineral; além de outras (opções reais arco-íris, de crescimento e de parada temporária da produção).

Antes de concluir a presente seção, enfatize-se que, no exemplo apresentado, a avaliação por opções reais resultou num valor de projeto superior àquele obtido mediante a avaliação pelo VPL, conforme largamente se divulga no meio financeiro. $\mathrm{O}$ exemplo tratava de um caso de monopólio, porém, quando a concorrência entre empresas é incorporada na avaliação, nem sempre isto é verdade, conforme este trabalho demonstra em seus resultados.

\section{Dilema do Prisioneiro}

O Dilema do Prisioneiro é um exemplo de jogo largamente difundido nos manuais de microeconomia e teoria dos jogos, como exemplo de jogo estático de informação completa. Nele, dois suspeitos são presos pela polícia; esta não possui evidência suficiente para os condenar, a menos que um deles confesse o crime. Os suspeitos são então mantidos em celas separadas e a polícia lhes explica as conseqüências das ações que eles podem tomar que, juntas, representam os perfis de estratégias do jogo. $\mathrm{O}$ ato de explicar as conseqüências são as regras do jogo. Caso nenhum dos suspeitos confesse, ambos serão sentenciados a um crime de pouca gravidade e pegarão um ano de cadeia. Se 
ambos confessam, serão sentenciados a dois anos de cadeia. Porém, se somente um deles confessar, este será imediatamente liberado e o outro será sentenciado e três anos de cadeia, sendo dois pelo crime e mais um por obstruir a justiça. Os prisioneiros decidem o que fazer separadamente, sem saber da decisão do outro; daí o caráter estático do jogo. Também é um jogo de informação completa, porque ambos conhecem a punição (ou pagamento) que cada um receberá com base no perfil de estratégias que for selecionado. O jogo Dilema do Prisioneiro, com base nessas propriedades, pode ser representado na sua forma normal pela seguinte matriz de pagamentos:

Figura 1: Matriz de Pagamentos do Jogo Dilema do Prisioneiro

\begin{tabular}{|c|c|c|c|}
\hline \multirow{2}{*}{\multicolumn{1}{c|}{}} & \multicolumn{2}{c|}{ Prisioneiro 2 } \\
\cline { 3 - 4 } & & Confessar & Não Confessar \\
\cline { 2 - 4 } & Confessar & $-2 ;-2$ & $0 ;-3$ \\
\cline { 2 - 4 } Prisioneiro 1 & Não Confessar & $-3 ; 0$ & $-1 ;-1$ \\
\cline { 2 - 4 } & &
\end{tabular}

$\mathrm{Na}$ matriz anterior, os pagamentos de cada jogador (prisioneiro) são representados pelo número de anos de sentença. O equilíbrio de Nash do jogo é o perfil de estratégias (Confessar; Confessar), porém, pode ser observado que (Não Confessar; Não Confessar) conduz a um resultado, onde os pagamentos individuais são simultaneamente mais eficientes para ambos os jogadores. $\mathrm{O}$ fato é que a estratégia Não Confessar é estritamente dominada pela estratégia Confessar, de modo que ela não é jogada. Na figura anterior, com os valores representados na matriz de pagamentos, isso fica claro, uma vez que nenhum dos prisioneiros irá arriscar-se a escolher a estratégia Não Confessar, porque eles não têm nenhuma garantia ou informação de que o outro fará o mesmo. Caso o outro prisioneiro escolha Confessar, o prisioneiro que não confessou acabará numa situação de prejuízo superior àquela correspondente ao equilíbrio de Nash do jogo. Quando, nas aplicações financeiras da teoria dos jogos, duas empresas fazem o papel dos prisioneiros, para sair da situação do Dilema do Prisioneiro seria necessário que ambas formassem um acordo de cooperação no sentido de selecionarem o perfil de estratégias mais eficiente para ambas simultaneamente em termos de geração de lucros. Ainda em relação à matriz de pagamentos da figura anterior, caso os valores zero, $-1,-2$ e -3 fossem substituídos por A, B, C e $\mathrm{D}$, respectivamente, qualquer jogo em que $\mathrm{A}>\mathrm{B}>\mathrm{C}>\mathrm{D}$ representaria uma situação de Dilema do Prisioneiro.

Outra propriedade importante do jogo Dilema do Prisioneiro, na forma representada na Figura 1, é a sua simetria, uma vez que: 
$\Pi_{1}\left(S_{1} ; S_{2}\right)=\Pi_{2}\left(S_{2} ; S_{1}\right)$

onde $\Pi_{i}$ representa o pagamento do jogador $i$ e $S_{i}$ a estratégia escolhida pelo jogador $i$.

\section{MOdelo}

O modelo temporal, com dois instantes de tempo, empregado nesta pesquisa, tem as seguintes premissas.

1 - Um setor produtivo está regulamentado pelo governo de um país (exemplo: mercado de fabricação de aço). As únicas duas empresas A e B que operam neste mercado produzem um bem intermediário com as mesmas especificações, podendo-se admitir que ele constitui um bem homogêneo e, além disso, admite-se que toda a oferta é comprada pelo mercado consumidor (indústria a jusante) para ser empregada na produção do bem final.

2 - Cada consumidor possui uma função de procura linear, sendo o preço do bem intermediário naquele mercado dado por $p=1-Q$, onde $Q$ é a quantidade total ofertada por ambas as empresas.

3 - Ambas as empresas empregam uma tecnologia linear de produção, de modo que para produzir uma unidade do bem intermediário é requerido o emprego de uma unidade de uma commodity (exemplo: minério de ferro) e possuem a mesma estrutura de custos, composta por um custo fixo $f$ e um custo marginal constante igual ao preço de uma unidade da commodity, definido como $c$, o qual varia ao longo do tempo de forma estocástica, seguindo um Movimento Geométrico Browniano [MGB]. A tecnologia utilizada é bastante flexível no que respeita à capacidade das empresas variarem o nível do output.

Ainda em relação ao preço da commodity, como ressaltam Dixit e Pindyck (1994), poder-se-ia argumentar que seria mais coerente uma modelagem do seu comportamento ao longo do tempo, como um Processo de Reversão à Média [MRM]. Porém os mesmos autores destacam que para dados inferiores a 30 anos, é estatisticamente difícil de se distinguir entre o MGB e o MRM, de modo que é admissível assumir o comportamento como um MGB.

4 - Ambas as empresas dispõem da mesma informação e método de cálculo do valor esperado e da volatilidade (representada no modelo por $\sigma$ ) do preço da commodity. Além disso, ambas consideram que esta volatilidade é constante no tempo. 
5 -Atualmente (instante inicial ou ano zero), a quantidade do bem intermediário que as empresas ofertam foi estabelecida pelo governo do país, com base na competição à la Cournot.

6 - O país é importador da commodity utilizada como input na fabricação do bem intermediário, de modo que o governo, mediante a regulamentação do mercado, tenta intervir diante de oscilações do seu preço. No próximo ano (ano um ou instante final), há dois cenários possíveis.

6A - O preço do input (ou custo marginal) evolui de forma desfavorável e para tentar compensar o preço mais elevado da commodity no mercado, o governo autoriza cada empresa a efetuar a contração da produção em exatamente $15 \%$. As empresas possuem neste cenário duas estratégias cada uma: contrair ou não alterar (a produção), sendo a decisão tomada simultaneamente, constituindo-se um jogo estático simétrico de informação completa. Para efeito deste trabalho, admite-se apenas o emprego de estratégias puras e a inexistência de acordos cooperativos entre as empresas.

6B - O preço do input evolui de forma favorável, e o governo concede incentivos para o aumento da produção nacional, mediante uma autorização a cada empresa de expandir produção em exatamente $5 \%$. Neste cenário cada empresa possui as estratégias de expandir ou não alterar.

Em ambos os cenários das hipóteses 6A e 6B, caso uma empresa opte por não alterar o nível da produção, ela fica obrigada pela regulamentação do mercado a ofertar a mesma quantidade do bem intermediário que já vinha ofertando no ano anterior (instante inicial).

Com base na modelagem do preço da commodity por meio do MGB, o modelo temporal pode ser representado por uma árvore binomial, conforme o modelo discreto no tempo de Cox, Ross e Rubinstein (1979). Nesta abordagem, como assinala Hull (1993), o movimento discreto no tempo de passeio aleatório do valor do ativo converge no limite de tempo, tendendo a zero para o MGB, desde que a taxa $u$ do movimento de subida em cada nó da árvore binomial, a taxa $d$ para um movimento de descida e a probabilidade neutra ao risco $z$ para um movimento de subida sejam selecionados de acordo com as seguintes equações, já levando em consideração que o intervalo de tempo na árvore binomial deste modelo é igual a um ano:

$$
u=e^{\sigma} ; \quad d=e^{-\sigma} ; \quad z=\frac{e^{r}-e^{-\sigma}}{e^{\sigma}-e^{-\sigma}}
$$

Na equação anterior, a variável $r$ corresponde à taxa livre de risco, assumida como a taxa Euribor de 12 meses (2,319\% ao ano em 07/04/2005, fonte: Diário 
Económico no 3606 - Portugal). Na Figura 2 representa-se a árvore binomial, onde o nó 1 dela representa o instante inicial e os nós 2 e 3 o instante final, sob cenário desfavorável e favorável, respectivamente. No caso dos nós 2 e 3 , observase a presença de um jogo, conforme as premissas $6 \mathrm{~A}$ e $6 \mathrm{~B}$, respectivamente. $\mathrm{O}$ lucro esperado no instante final, independentemente de qual situação do jogo esteja sendo analisada, é sempre calculado a partir da seguinte equação:

$E\left[\pi_{i}\right]=z \pi_{i}^{(2)}+(1-z) \pi_{i}^{(3)} \quad i=A, B$

\section{Figura 2: Representação do Modelo Temporal}

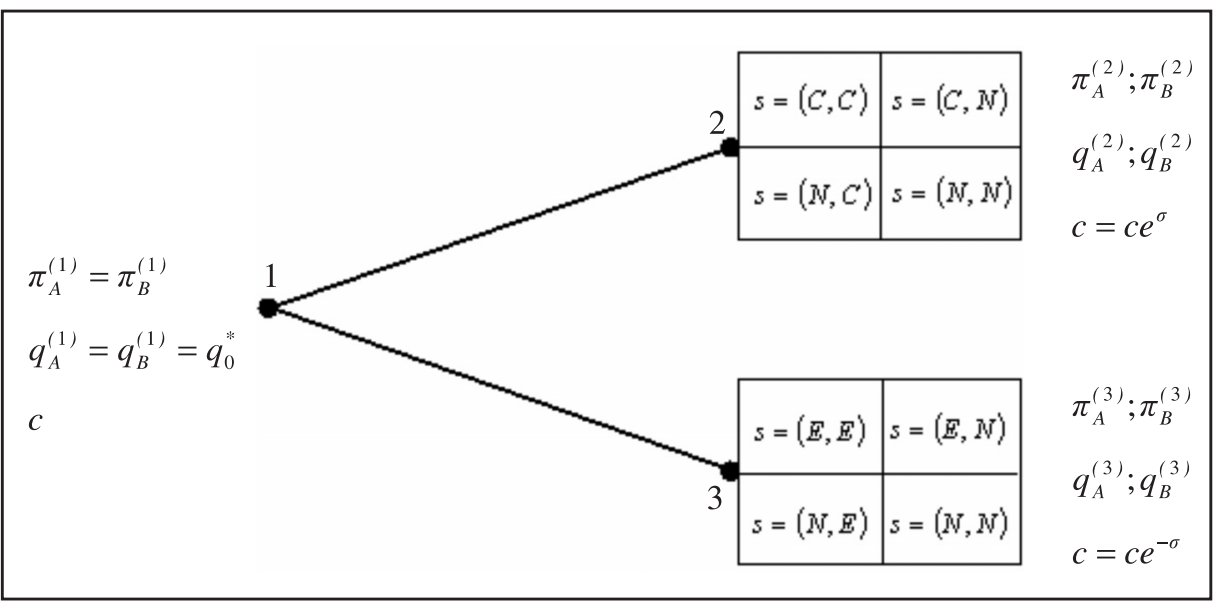

\section{Lucro Esperado Considerando que as Opções Reais São Comuns}

Esta situação é mais coerente com o mundo real. Neste caso, a equipe gerencial emprega um modelo de projeção de lucros completo, considerando as flexibilidades gerenciais juntamente com as incertezas em face do futuro, ou seja, admitindo a existência das opções reais. Adicionalmente, os gestores da empresa levam em consideração as possíveis ações estratégicas da concorrência, fazendo com que o modelo admita a existência de um jogo de dois jogadores.

No instante inicial, nó 1 da árvore binomial, ambas as empresas têm o mesmo lucro:

$\pi_{i}^{(1)}=\left(1-q_{i}-q_{j}\right) q_{i}-c q_{i}-f ; \quad i, j=A, B ; \quad i \neq j$ 
A oferta de cada empresa é obtida por meio da maximização do lucro em relação à quantidade:

$$
\frac{\partial \pi_{i}^{(1)}}{\partial q_{i}}=0 ; \quad i=A, B ; \quad \Rightarrow \quad q_{A}^{(1)}=q_{B}^{(1)}=q_{0}^{*}=\frac{1-c}{3}
$$

No instante inicial as seguintes condições de contorno têm de ser atendidas para a quantidade ofertada por cada empresa e para o preço de mercado:

$$
\begin{aligned}
& q_{0}^{*}>0 \Rightarrow \frac{1-c}{3}>0 \Rightarrow c<1 \Rightarrow \forall c \in(0,1) \\
& p=1-q_{A}^{(1)}-q_{B}^{(1)}>0 \Rightarrow 1-2\left(\frac{1-c}{3}\right)>0 \Rightarrow c>-\frac{1}{2} \Rightarrow \forall c \in(0,+\infty)
\end{aligned}
$$

\section{Ano Um - Cenário Favorável}

Nesta situação, cada empresa pode exercer ou não a sua opção real de expandir a oferta em 5\%. Há um jogo estático simétrico de informação completa, em que somente se admite o uso de estratégias puras, expresso na sua forma normal por: $G=[I, S, \pi(s)]$, onde: $I=\{A, B\}$, é o conjunto de jogadores (empresas $A$ e $B$ ); $S_{A}=\{E, N\}, \quad S_{B}=\{E, N\}$, são os conjuntos de estratégias puras das empresas $A$ e $B$, onde $E$ significa expandir e $N$ significa não alterar, resultando no espaço de estratégias puras do jogo $S=S_{A} \times S_{B}=\{(E, E) ;(E, N) ;(N, E) ;(N, N)\}$, onde cada elemento é um perfil $s$ de estratégias puras; $\pi(s)=\left\{\pi_{A}(s), \pi_{B}(s)\right\}$, é a função de pagamentos combinada, onde:

$$
\pi(s)=\left[\begin{array}{ll}
\pi_{A}(E, E) ; \pi_{B}(E, E) & \pi_{A}(E, N) ; \pi_{B}(E, N) \\
\pi_{A}(N, E) ; \pi_{B}(N, E) & \pi_{A}(N, N) ; \pi_{B}(N, N)
\end{array}\right]
$$

Para cada um dos quatro perfis $s$ de estratégias puras admissíveis de serem jogados, os elementos das matrizes de pagamento A e B das empresas são da forma:

$$
\begin{aligned}
& \pi_{A}(E, E)=\pi_{B}(E, E)=\left(1-1,05 q_{0}^{*}-1,05 q_{0}^{*}\right) \cdot 1,05 q_{0}^{*}-1,05 q_{0}^{*} c \exp (-\sigma)-f \\
& \pi_{A}(E, E)=\pi_{B}(E, E)=1,05 q_{0}^{*}-2,205\left(q_{0}^{*}\right)^{2}-1,05 q_{0}^{*} c \exp (-\sigma)-f
\end{aligned}
$$




$$
\begin{aligned}
& \pi_{A}(N, N)=\pi_{B}(N, N)=\left(1-q_{0}^{*}-q_{0}^{*}\right) \cdot q_{0}^{*}-q_{0}^{*} c \exp (-\sigma)-f \\
& \pi_{A}(N, N)=\pi_{B}(N, N)=q_{0}^{*}-2\left(q_{0}^{*}\right)^{2}-q_{0}^{*} c \exp (-\sigma)-f \\
& \pi_{A}(E, N)=\pi_{B}(N, E)=\left(1-1,05 q_{0}^{*}-q_{0}^{*}\right) \cdot 1,05 q_{0}^{*}-1,05 q_{0}^{*} c \exp (-\sigma)-f \\
& \pi_{A}(E, N)=\pi_{B}(N, E)=1,05 q_{0}^{*}-2,1525\left(q_{0}^{*}\right)^{2}-1,05 q_{0}^{*} c \exp (-\sigma)-f \\
& \pi_{A}(N, E)=\pi_{B}(E, N)=\left(1-q_{0}^{*}-1,05 q_{0}^{*}\right) \cdot q_{0}^{*}-q_{0}^{*} c \exp (-\sigma)-f \\
& \pi_{A}(N, E)=\pi_{B}(E, N)=q_{0}^{*}-2,05\left(q_{0}^{*}\right)^{2}-q_{0}^{*} c \exp (-\sigma)-f
\end{aligned}
$$

Com base na função de pagamentos combinada expressa em (8) e nas equações (9) a (12), as matrizes de pagamentos das empresas A e B podem ser escritas como:

$$
\pi_{A}(s)=\left[\begin{array}{ll}
\pi_{A}(E, E) & \pi_{A}(E, N) \\
\pi_{A}(N, E) & \pi_{A}(N, N)
\end{array}\right] ; \quad \pi_{B}(s)=\left[\begin{array}{ll}
\pi_{A}(E, E) & \pi_{A}(N, E) \\
\pi_{A}(E, N) & \pi_{A}(N, N)
\end{array}\right]
$$

Sejam os termos:

$$
\begin{aligned}
& a_{1}=\pi_{A}(E, E)-\pi_{A}(N, E)=0,05 q_{0}^{*}-0,155\left(q_{0}^{*}\right)^{2}-0,05 q_{0}^{*} c \exp (-\sigma) \\
& a_{2}=\pi_{A}(N, N)-\pi_{A}(E, N)=-0,05 q_{0}^{*}+0,1525\left(q_{0}^{*}\right)^{2}+0,05 q_{0}^{*} c \exp (-\sigma)
\end{aligned}
$$

Se for subtraído $\pi_{A}(N, E)$ na coluna 1 da matriz de pagamentos da empresa A e $\pi_{A}(E, N)$ na coluna 2, a matriz de pagamentos daquela empresa, representada em (13) torna-se:

$$
\pi_{A}(s)=\left[\begin{array}{cc}
a_{1} & 0 \\
0 & a_{2}
\end{array}\right]
$$

Segundo Weibull (1996), tratando-se de um jogo duplamente simétrico de duas empresas como em (16), onde $\pi_{B}(s)=\left[\pi_{A}(s)\right]^{T}=\pi_{A}(s)$ e no qual cada jogador possui apenas duas estratégias puras (aqui definidas como expandir, não alterar), o jogo do nó 3 da árvore binomial pode ser classificado nas seguintes categorias. 
- Categoria A - ocorre quando $a_{1}<0 ; a_{2}>0$, sendo que a segunda estratégia (não expandir) é a melhor resposta de cada empresa para qualquer estratégia utilizada pela sua rival. O jogo possui um equilíbrio de Nash simétrico e estrito, definido por $\theta^{\text {Nash }}=\{(N, N)\}$. Assim, quando o jogo se classifica nesta categoria, ambas as empresas não exercem a sua opção real de expandir.

. Categoria B - ocorre quando $a_{1}<0 ; a_{2}<0$. Nesse caso cada estratégia pura é a melhor resposta de cada empresa, quando a rival utiliza a outra estratégia pura. $\mathrm{O}$ jogo possui dois equilíbrios de Nash assimétricos e estritos em estratégias puras, definido por $\theta^{\text {Nash }}=\{(E, N) ;(N, E)\}$.

- Categoria C - ocorre quando $a_{1}>0 ; a_{2}<0$. Nesse caso, recaindo-se na categoria $\mathrm{A}$, sendo que a primeira estratégia (expandir) é a melhor resposta de cada empresa para qualquer estratégia utilizada pela sua rival e tendo o jogo um equilíbrio de Nash definido por $\theta^{\text {Nash }}=\{(E, E)\}$. Portanto, nesta categoria, ambas as empresas exercem a sua opção real de expandir.

Há ainda uma quarta categoria possível, com $a_{1}>0 ; a_{2}>0$, a qual não ocorre neste modelo. Para que o termo ${ }^{a_{1}}$ seja positivo, é necessário com base em (14) que:

$a_{1}>0 \Leftrightarrow \sigma>-\ln \left(\frac{0,155 c-0,005}{0,15 c}\right)$

Para que o termo $a_{2}$ seja positivo, é necessário com base em (15) que:

$a_{2}>0 \Leftrightarrow \sigma<-\ln \left(\frac{0,1525 c-0,0025}{0,15 c}\right)$

Para garantir que se trabalha sempre com valores de volatilidade e preço positivos, a condição de contorno global $c \in(0,03226 ; 1)$, baseada nas expressões (9) a (12), (17) e (18) deve ser atendida.

A partir das categorias definidas e das expressões (17) e (18), na figura a seguir, apresenta-se a solução gráfica do jogo no nó 3 da árvore binomial para valores da volatilidade variando no intervalo $(0 \% ; 100 \%$ ]; e para valores do custo marginal inicial variando no intervalo $(0,03226 ; 0,80)$ : 
Figura 3: Solução do Jogo no Cenário Futuro Favorável

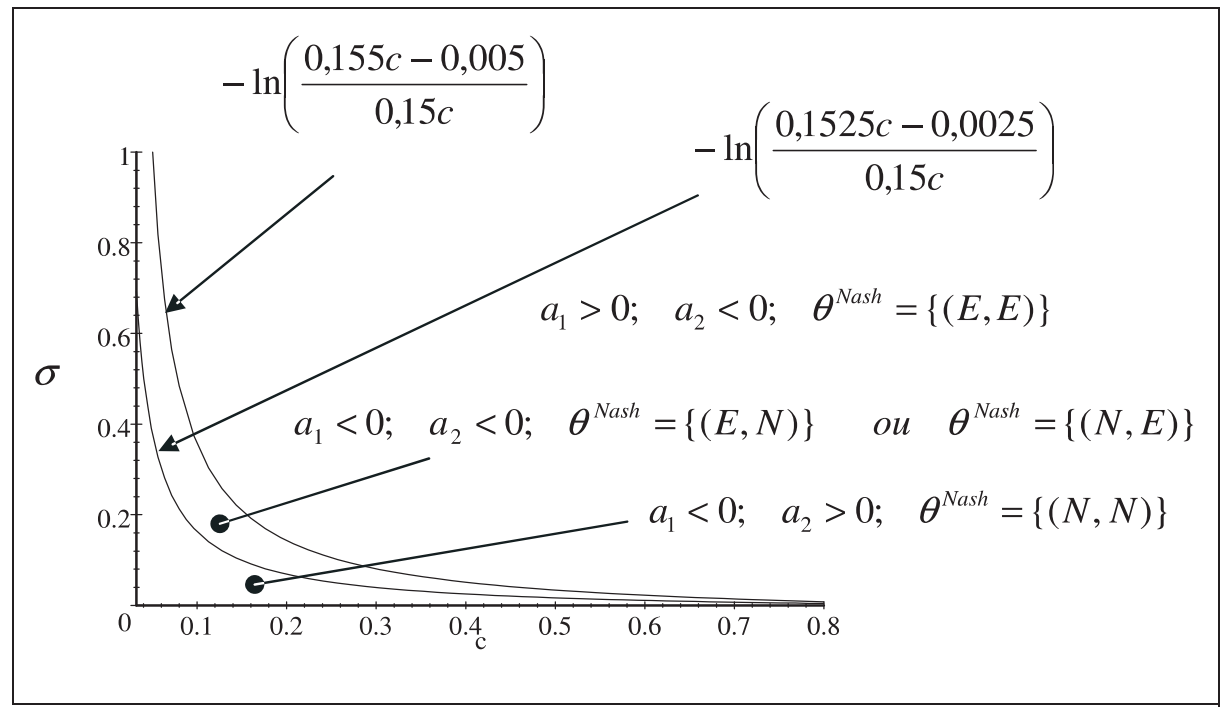

Uma questão importante na resolução do jogo anterior ocorre, quando este se classifica na categoria B. Nesta situação, o equilíbrio de Nash pressupõe que uma das empresas exerça a expansão, enquanto a outra não faça o exercício da sua opção real. Porém, como a melhor estratégia individual para cada uma das empresas nesse caso é expandir, nenhum dos dois equilíbrios de Nash desta categoria neste modelo é eficiente à Pareto simultaneamente para as duas empresas, uma vez que para $\theta^{\text {Nash }}=\{(E, N) ;(N, E)\}$, tem-se:

$$
\pi_{A}(E, N)>\pi_{A}(N, E) \Leftrightarrow \sigma>-\ln \left(\frac{0,1025 c+0,0475}{0,15 c}\right) \Rightarrow \sigma>0 ; \forall c \in(0 ; 1)
$$

$$
\therefore\left\{\begin{array}{l}
\pi_{A}(N, E)<\pi_{A}(E, N) \\
\pi_{B}(N, E)>\pi_{B}(E, N)
\end{array} ; \quad \forall c \in(0 ; 1)\right.
$$

A forma aqui adotada de resolver este jogo nesta categoria está baseada nas expectativas exógenas ou pontos focais, quando cada jogador forma expectativas acerca do outro jogador com base em informações que não fazem uso da estrutura matemática do jogo. Segundo Mas-Colell, Whinston e Green (1995), os resultados da abordagem exógena podem ser culturalmente determinados e, no caso deste trabalho, são aplicados à hipótese em que uma das empresas (por exemplo, A) é líder no setor (comparativamente à empresa B), equivalendo à condição em que ela selecionaria sempre primeiro a sua 
estratégia a adotar nesta situação, sendo depois seguida por B. É importante reparar que no mercado em análise, em princípio, ambas as empresas são idênticas em termos de produção e estrutura. Porém pode ser admitido que as empresas A e B atuam também em outros mercados em nível internacional, tendo a empresa A, no contexto mundial, mais poder que a empresa B. Dessa forma, a empresa B tentar assumir o papel de líder neste mercado particular que aqui é analisado poderia ser sinalizado para a empresa A como uma tentativa de inversão de papéis, dando início a uma guerra competitiva entre as duas, situação que não seria nada interessante para a empresa B.

Ao se admitir que a empresa A é líder e, por conseqüência, sempre seleciona primeiro a sua estratégia gerencial conforme o cenário, ela sempre selecionará a estratégia de expandir, quando o jogo estiver na categoria $\mathrm{B}$, baseado em (19), uma vez que neste caso $\pi_{A}(E, N)>\pi_{A}(N, E)$. Feita a seleção da estratégia de exercer a opção real de expansão pelos gerentes da empresa $\mathrm{A}$, a empresa $\mathrm{B}$ se vê forçada a selecionar a estratégia de não alterar nada, uma vez que, na categoria B do jogo, o seguinte é válido:

$$
a_{1}<0 \Leftrightarrow \pi_{A}(N, E)>\pi_{A}(E, E) \quad \therefore \quad \pi_{B}(E, N)>\pi_{B}(E, E)
$$

Portanto a solução do jogo no cenário favorável expressa na Figura 3, quando este se classifica na categoria $\mathrm{B}$ é a seleção do perfil de estratégias $s=(E, N)$ pelas empresas.

\section{Ano Um - Cenário Desfavorável}

Nesta situação, cada empresa pode exercer ou não a sua opção real de contrair a oferta em 15\%. Mais uma vez, há um jogo estático simétrico de informação completa, onde somente se admite o uso de estratégias puras, expresso na sua forma normal por:

$G=[I, S, \pi(s)]$, onde: $I=\{A, B\}$, é o conjunto de jogadores (empresas A e B); $S_{A}=\{C, N\}, \quad S_{B}=\{C, N\}$, são os conjuntos de estratégias puras das empresas A e $\mathrm{B}$, onde $C$ significa contrair e $N$ significa não alterar, resultando no espaço de estratégias puras do jogo $S=S_{A} \times S_{B}=\{(C, C) ;(C, N) ;(N, C) ;(N, N)\}$, onde cada elemento é um perfil $s$ de estratégias puras; $\pi(s)=\left\{\pi_{A}(s), \pi_{B}(s)\right\}$, é a função de pagamentos combinada, onde neste caso:

$$
\pi(s)=\left[\begin{array}{ll}
\pi_{A}(C, C) ; \pi_{B}(C, C) & \pi_{A}(C, N) ; \pi_{B}(C, N) \\
\pi_{A}(N, C) ; \pi_{B}(N, C) & \pi_{A}(N, N) ; \pi_{B}(N, N)
\end{array}\right]
$$


Para cada um dos quatro perfis $\mathrm{s}$ de estratégias puras admissíveis de serem jogados, os elementos das matrizes de pagamento A e B das empresas são da forma:

$$
\begin{aligned}
& \pi_{A}(C, C)=\pi_{B}(C, C)=\left(1-0,85 q_{0}^{*}-0,85 q_{0}^{*}\right) \cdot 0,85 q_{0}^{*}-0,85 q_{0}^{*} c \exp (\sigma)-f \\
& \pi_{A}(C, C)=\pi_{B}(C, C)=0,85 q_{0}^{*}-1,445\left(q_{0}^{*}\right)^{2}-0,85 q_{0}^{*} c \exp (\sigma)-f \\
& \pi_{A}(N, N)=\pi_{B}(N, N)=\left(1-q_{0}^{*}-q_{0}^{*}\right) \cdot q_{0}^{*}-q_{0}^{*} c \exp (\sigma)-f \\
& \pi_{A}(N, N)=\pi_{B}(N, N)=q_{0}^{*}-2\left(q_{0}^{*}\right)^{2}-q_{0}^{*} c \exp (\sigma)-f \\
& \pi_{A}(C, N)=\pi_{B}(N, C)=\left(1-0,85 q_{0}^{*}-q_{0}^{*}\right) \cdot 0,85 q_{0}^{*}-0,85 q_{0}^{*} c \exp (\sigma)-f \\
& \pi_{A}(C, N)=\pi_{B}(N, C)=0,85 q_{0}^{*}-1,5725\left(q_{0}^{*}\right)^{2}-0,85 q_{0}^{*} c \exp (\sigma)-f \\
& \pi_{A}(N, C)=\pi_{B}(C, N)=\left(1-q_{0}^{*}-0,85 q_{0}^{*}\right) \cdot q_{0}^{*}-q_{0}^{*} c \exp (\sigma)-f \\
& \pi_{A}(N, C)=\pi_{B}(C, N)=q_{0}^{*}-1,85\left(q_{0}^{*}\right)^{2}-q_{0}^{*} c \exp (\sigma)-f
\end{aligned}
$$

A metodologia de resolução no cenário desfavorável segue o mesmo raciocínio que foi adotado para a análise da opção de expansão. Neste caso os termos $a_{1}$ e $a_{2}$ são expressos por:

$$
\begin{aligned}
& a_{1}=\pi_{A}(C, C)-\pi_{A}(N, C)=-0,15 q_{0}^{*}+0,405\left(q_{0}^{*}\right)^{2}+0,15 q_{0}^{*} c \exp (\sigma) \\
& a_{2}=\pi_{A}(N, N)-\pi_{A}(C, N)=0,15 q_{0}^{*}-0,4275\left(q_{0}^{*}\right)^{2}-0,15 q_{0}^{*} c \exp (\sigma)
\end{aligned}
$$

Para que o termo $a_{1}$ seja positivo, é necessário com base em (26) que:

$$
a_{1}>0 \Leftrightarrow \sigma>\ln \left(\frac{0,405 c+0,045}{0,45 c}\right)
$$

Para que o termo $a_{2}$ seja positivo, é necessário com base em (27) que:

$$
a_{2}>0 \Leftrightarrow \sigma<\ln \left(\frac{0,4275 c+0,0225}{0,45 c}\right)
$$


Para garantir que se trabalha sempre com valores de volatilidade e preço positivos, a condição de contorno global $c \in(0 ; 1)$, baseada nas expressões (22) a (25), (28) e (29) deve ser atendida.

Com base nas categorias anteriormente definidas e nas expressões (28) e (29), na figura a seguir, apresenta-se a solução gráfica do jogo no nó 2 da árvore binomial para os mesmos valores usados no cenário favorável da volatilidade, variando no intervalo $(0 \% ; 100 \%$ ] e do custo marginal inicial, variando no intervalo $(0,03226 ; 0,80)$ :

\section{Figura 4: Solução do Jogo no Cenário Futuro Desfavorável}

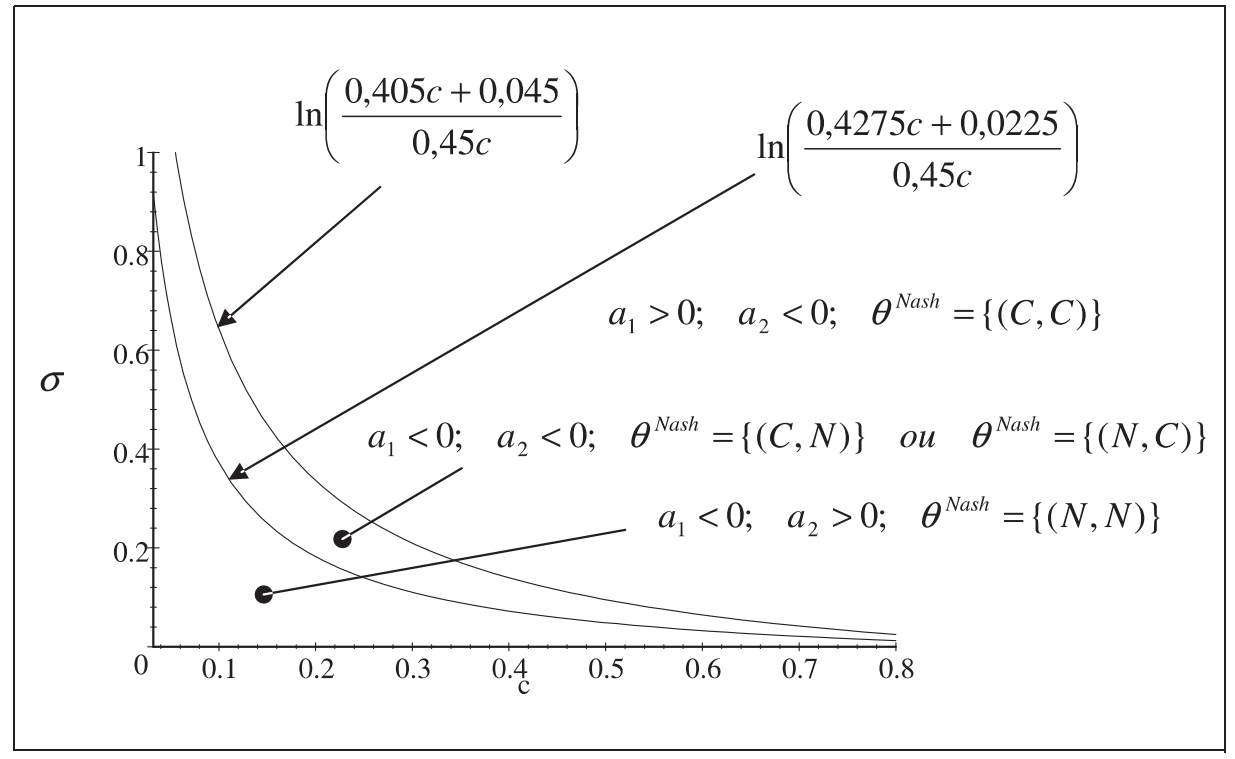

No caso do jogo se classificar na categoria B para o caso do cenário desfavorável, tem-se:

$\pi_{A}(N, C)>\pi_{A}(C, N) \Leftrightarrow \sigma<\ln \left(\frac{0,2775 c+0,1725}{0,45 c}\right)$

Uma vez que:

$\left(\frac{0,2775 c+0,1725}{0,45 c}\right)>\left(\frac{0,405 c+0,045}{0,45 c}\right) \forall c \in(0 ; 1)$ 
Tem-se:

$\pi_{A}(N, C)>\pi_{A}(C, N) ; \quad a_{1}, a_{2}<0 \quad \forall c \in(0 ; 1)$

Baseados na expressão anterior e na liderança da empresa A, os gerentes dela se posicionam na estratégia de não alterar nada no que tange à sua oferta, enquanto a empresa B se vê forçada a selecionar a estratégia de exercer a opção de contração, uma vez que, na categoria B do jogo, o seguinte é válido:

$a_{2}<0 \Leftrightarrow \pi_{A}(C, N)>\pi_{A}(N, N) \quad \therefore \quad \pi_{B}(N, C)>\pi_{B}(N, N)$

Portanto a solução do jogo no cenário desfavorável expressa na Figura 4, quando este se classifica na categoria $\mathrm{B}$, é a seleção do perfil de estratégias $s=(N, C)$ pelas empresas.

\section{Lucro Esperado Quando se Ignora a Existência das Opções Reais}

Nesse contexto ortodoxo, equivale a dizer que a ignorância gerencial acerca da existência das opções reais e, consequientemente, a desconsideração da flexibilidade de decisões gerenciais, no que diz respeito à possibilidade de se usar mais de uma estratégia de acordo com o cenário futuro que se descortine, faz com que, independentemente do nó da árvore binomial em que estejam posicionadas no instante final de tempo (ano um) e da volatilidade, as empresas sempre adotam a estratégia de não alterar a quantidade ofertada, de modo que equivale a sempre ser adotado o perfil de estratégias $s=(N, N)$, ou seja, nessa situação, o modelo de projeção de lucros futuros, além de não incorporar as opções reais, não admite a existência do jogo de dois jogadores.

\section{Lucro Esperado Considerando as Opções Reais como Exclusivas}

Este caso, muito comum nos trabalhos da literatura de opções reais, é aquele em que a equipe gerencial emprega um modelo financeiro de gestão ou valoração mais desenvolvido que no caso ortodoxo, uma vez que a equipe admite a existência das opções reais; porém erra ao não incorporar também no modelo o jogo de dois jogadores, ignorando a detenção das mesmas flexibilidades (estratégias) por parte da concorrência. Nessa situação, são necessárias mudanças no modelo aqui utilizado inicialmente para considerar o caso em que a opção de expandir é assumida pelos gerentes da empresa A, por exemplo, como sendo uma opção exclusiva da empresa. Num caso em que esta opção fosse exclusiva da empresa $\mathrm{A}$, isso seria equivalente a no nó 3 da árvore binomial a empresa A dispor das duas estratégias puras, expandir e não alterar 
a produção, enquanto a empresa $\mathrm{B}$ somente dispõe da estratégia pura não alterar. Os perfis de estratégias puras admissíveis neste novo jogo são: $s=\{(E, N)\}$ e $s=\{(N, N)\}$. Nesse caso, com base em (13), a matriz de pagamentos da empresa $A$ fica:

$$
\pi_{A}(s)=\left[\begin{array}{l}
\pi_{A}(E, N) \\
\pi_{A}(N, N)
\end{array}\right]
$$

Assim, o perfil $s=\{(E, N)\}$ é adotado pelas empresas se $a_{2}<0$, ou seja, conforme (18):

$$
s=\{(E, N)\} \Leftrightarrow \sigma>-\ln \left(\frac{0,1525 c-0,0025}{0,15 c}\right)
$$

Caso contrário, é adotado o perfil $s=\{(N, N)\}$. No caso da opção de contração, que está disponível no cenário desfavorável, vale o mesmo tipo de raciocínio, sendo que a empresa A dispõe de duas estratégias puras, contrair e não alterar a produção, enquanto a empresa $B$ somente dispõe da estratégia pura de não alterar. Os perfis de estratégias puras admissíveis neste caso são:

$s=\{(C, N)\}$ e $s=\{(N, N)\}$, sendo que:

$s=\{(C, N)\} \Leftrightarrow \sigma>\ln \left(\frac{0,4275 c+0,0225}{0,45 c}\right)$

Caso contrário, também é adotado o perfil $s=\{(N, N)\}$.

\section{UMA APLICAÇÃO EMPÍRICA}

A Tabela 1 do Apêndice apresenta o lucro no cenário favorável, $\Pi_{3}$, lucro no cenário desfavorável, $\Pi_{2}$, e o lucro esperado no instante final, $E[\Pi]$, todos eles obtidos para a empresa $\mathrm{A}$, segundo todas as situações que foram analisadas neste trabalho e considerando um custo marginal inicial admitido como igual a 0,06. Este valor atende a todas as condições de contorno calculadas. Também para efeito de cálculos foi considerado um custo fixo de 0,05 e a volatilidade variando entre $5 \%$ e $100 \%$. Observando os resultados, pode ser verificado que para o caso da opção de expansão, disponível no 
cenário favorável, a consideração da exclusividade da opção real sempre permite obter lucros futuros superiores, comparativamente ao caso em que não se considera a flexibilidade, uma vez que na situação de exclusividade, a opção somente é exercida, quando o lucro decorrente do perfil $s=\{(N, N)\}$ é inferior ao do perfil $s=\{(E, N)\}$. Isto é compatível com o resultado largamente difundido na literatura e no meio financeiro de que as opções reais, quando comparadas a métodos ortodoxos de avaliação (ou gestão), sempre permitem aumentar o valor (ou o lucro) de uma empresa, quando em presença de incertezas significativas. Porém, quando se assume como no mundo real que a mesma opção real não é de fato exclusiva, o método ortodoxo de se ignorar a flexibilidade e, consequientemente, a existência da opção real e da flexibilidade de estratégias gerenciais, pode conduzir a lucros superiores àqueles obtidos mediante a gestão pelas opções reais. No caso analisado, esta situação ocorreu, quando ambas as empresas exerciam as suas opções de expandir. Isso ocorreu porque, neste caso, a equação (9) assumiu valores inferiores aos da equação (10). Apesar de o perfil de estratégias neste caso que conduz ao maior lucro para as empresas ser aquele em que nenhuma delas exerce a sua opção real, as decisões das empresas são tomadas com base em sua racionalidade individual e não coletiva, uma vez que aqui se trata de um jogo não cooperativo. Assim, recai-se numa situação similar ao jogo do Dilema do Prisioneiro. Para o caso da opção de contração, disponível no cenário desfavorável, os resultados foram coerentes com a idéia difundida no meio financeiro; sempre que estratégias baseadas no exercício das opções reais foram consideradas, se obtiveram lucros superiores àqueles obtidos pelo método ortodoxo. Mais ainda, no caso em que se assumiu que a opção era comum, por ocasião do seu exercício, o lucro sempre foi superior em relação ao caso em que se considerou a exclusividade. Isso ocorreu porque, no caso da opção de contração, para valores da volatilidade compreendidos no intervalo entre $57,8 \%$ e $94,3 \%$, os perfis de estratégias jogados pelas duas empresas são $s=\{(C, N)\}$ e $s=\{(N, C)\}$ no caso que considera a exclusividade, e no caso que considera a não exclusividade da opção real, respectivamente. Dentro deste intervalo, ambos os perfis conduzem a lucros superiores àqueles que são obtidos para o perfil $s=\{(N, N)\}$; entretanto, conforme (30), na categoria B do jogo $\pi_{A}(N, C)>\pi_{A}(C, N)$, sempre. Já para valores de volatilidade superiores a $94,3 \%$, o perfil $s=\{(C, N)\}$ é jogado no caso da exclusividade e $s=\{(C, C)\}$ é jogado no caso da não exclusividade, sendo que, conforme (22) e (24), $\pi_{A}(C, C)>\pi_{A}(C, N)$ sempre. Neste último caso, quando a opção real não é exclusiva, as duas empresas, ao contraírem suas ofertas, acarretam a elevação do preço de mercado do bem intermediário que elas produzem, tornando o lucro da empresa $\mathrm{A}$ superior àquele que é obtido no caso da 
exclusividade. Além disso, a empresa A produz a mesma quantidade que no caso da exclusividade, sendo que o custo variável total é idêntico sob ambos os critérios. Entretanto, como a empresa B não detém a opção real no critério de exclusividade, a empresa $\mathrm{A}$ acaba por auferir uma receita total inferior àquela recebida no critério de não exclusividade, pois a maior oferta da empresa $\mathrm{B}$ acaba por causar impacto no preço de mercado do bem mais reduzido que aquele do caso em que as opções reais são comuns.

\section{Conclusão}

Este trabalho comparou o lucro esperado de uma empresa, quando se ignora a existência das flexibilidades gerenciais para adoção de estratégias segundo o cenário futuro, quando se leva em consideração a existência destas flexibilidades, admitindo-se que são exclusivas e quando se assume que estas existem e são comuns. Os resultados mostraram que, dependendo do tipo de opção real que se detém, mesmo a empresa sendo líder de mercado na escolha da sua estratégia gerencial a adotar e de estar diante de volatilidades significativas, nem sempre a gestão de negócios por meio das opções reais conduz ao melhor resultado para as empresas em termos de lucro.

No modelo apresentado neste trabalho, para o caso da opção real de contração disponível no cenário desfavorável, a gestão pelo método das opções reais, considerando que as opções reais são comuns, além de modelar mais corretamente o ambiente competitivo, foi o método que melhor contribuiu na forma de gerenciar, uma vez que, nesta abordagem, não somente os gerentes das duas empresas enxergam a existência da estratégia de contrair a produção, como também conduz aos maiores valores de lucro, em presença de volatilidade elevada (> 57,8\%, neste modelo). Para valores inferiores de volatilidade, é indiferente usar qualquer dos métodos de gestão. Já para o caso da opção de expansão disponível no cenário favorável, caso exista a exclusividade (ou monopólio) do direito de exercer a opção real por parte da empresa dominante, a gestão por opções reais seria o método que mais contribuiria em termos de lucro. Já no caso de a opção real ser comum, utilizar opções reais como método de gestão somente seria útil, se a volatilidade não fosse demasiadamente elevada $(<73,9 \%$, neste modelo). Para valores acima dela, o emprego da gestão ortodoxa, por meio do VPL, seria a forma de gerenciar que mais contribuiria, em termos de geração de lucro.

Artigo recebido em 04.11.2005. Aprovado em 16.03.2006. 


\section{ReferênCIAS BibliográficAs}

Brennan, M. J., \&

Schwartz, E. S. (1985).

Evaluating natural resource investments. Journal of Business, 58(2), 135-158.

Copeland, T., \&

Antikarov, V. (2002).

Opções reais. Rio de Janeiro: Campus.

Cox, J. C.,

Ross, S. A., \&

Rubinstein, M. (1979).

Option pricing: a simplified approach. Journal of Financial Economics, 7(3), 229-263.

Dixit, A. K., \&

Pindyck, R. S. (1994).

Investment under uncertainty. New Jersey: Princeton University Press.

\section{Hull, J. (1993).}

Options, futures, and other derivative securities (2a ed.). New Jersey: Prentice Hall-Englewood Cliffs.

Kensinger, J. W. (1987).

Adding the value of active management into the capital budgeting equation. Midland Corporate Finance Journal, 5(1), 31-42.

Kulatilaka, N. (1993).

The value of flexibility: the case of a dual-fuel industrial steam boiler. Financial Management, 22(3), 271280.
Lopes, W. P. de (2004).

Uma abordagem para aplicação integrada de cenários de estratégia com avaliação de opções reais em telecomunicações. Dissertação de Mestrado. Pontifícia Universidade Católica do Rio de Janeiro, Rio de Janeiro, RJ, Brasil.

Mas-Colell, A.,

Whinston, M. D., \&

Green, J. R. (1995).

Microeconomic theory. New York: Oxford University Press.

Margrabe, W. (1978).

The value of an option to exchange one asset for another. Journal of Finance, 33(1), 177-186.

Pereira, P. J., \&

Armada, M. R. (2003).

The value and timing of shared real options with random maturity. Recuperado em 10 março, 2006, de http://www.realoptions.org/ papers2003/pereira_armada.pdf

Perlitz, M.,

Peske, T., \&

Schrank, R. (1999).

Real options valuation: the new frontier in R\&D project evaluation? R\&D Management, 29(3), 255-269.

Pindyck, R. S. (1988).

Irreversible investment, capacity choice, and the value of the firm. American Economic Review, 78(5), 969-985. 
Rocha, A. B. S. da (2005).

Opções reais e teoria dos jogos como ferramentas combinadas para avaliar e comparar opções exclusivas e comuns de empresas em mercados duopolistas. Revista de Economia e Administração, 4(1), 1-26.

Titman, S. (1985).

Urban land prices under uncertainty. American Economic Review, 75(3), 505-514.
Tourinho, O. A. F. (1979).

The option value of reserves of natural resources [Working Paper $\mathrm{N}^{\circ}$ 94]. University of California at Berkeley.

Trigeorgis, L., \&

Mason, S. P. (1987).

Valuing managerial flexibility. Midland Corporate Finance Journal, 5(1), 1421.

Weibull, J. (1996).

Evolutionary game theory (2a ed.). Cambridge: The MIT Press. 


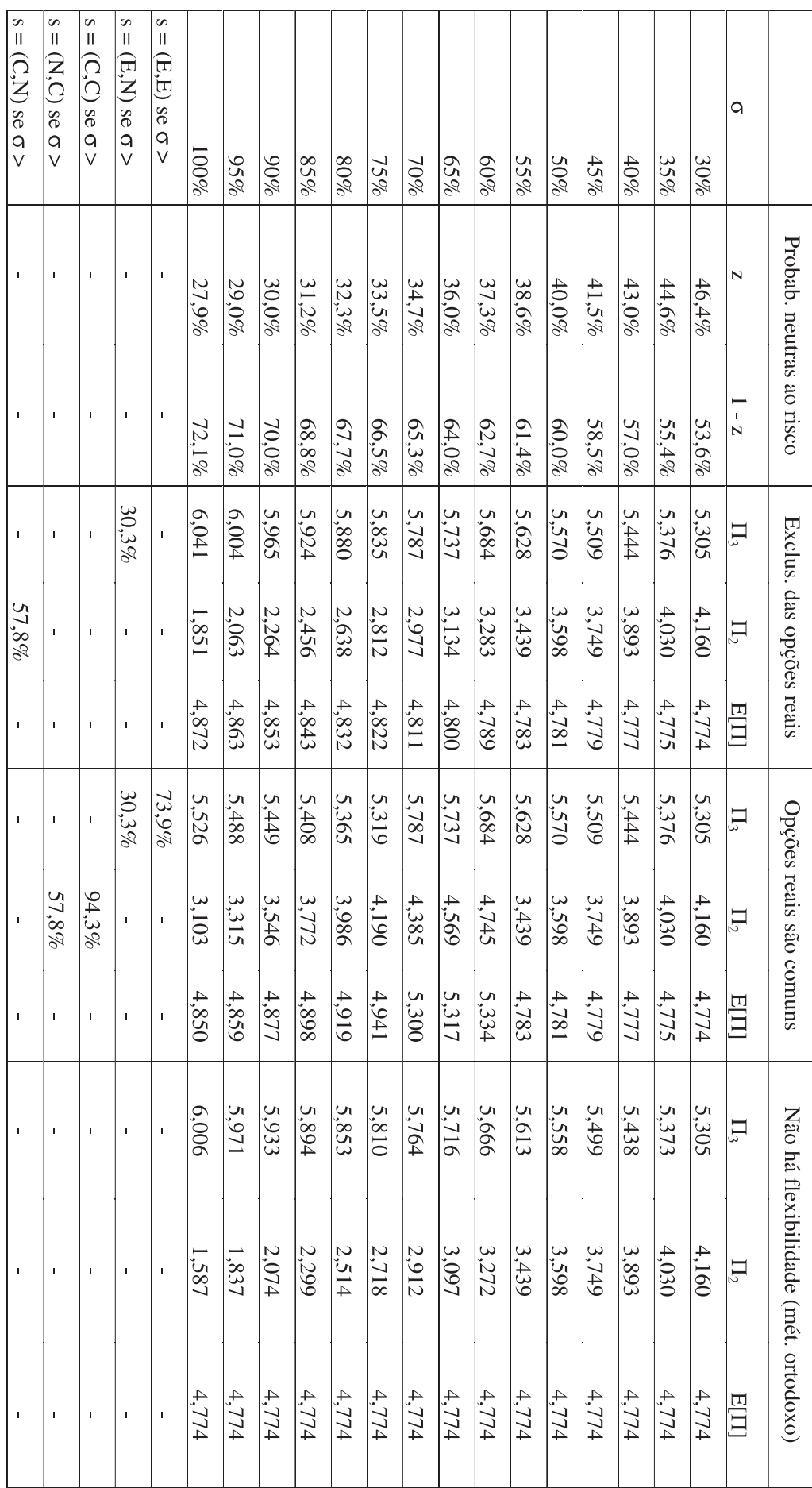

